\title{
Yaşlılarda ölçülen boy uzunluğu ve diz yüksekliğinden hesaplanan boy uzunluğu değerlerinin incelenmesi
}

* Sorumlu Yazar / Corresponding Author: Sibel Hınçal Antropoloji Anabilim Dalı Ankara/Türkiye

E-posta: sibelhincal@yahoo.com

\author{
Sibel Hande Hınçal ${ }^{1 *}$, Timur Gültekin ${ }^{2} \odot$
}

1 M.A., Doktora Öğrencisi | Ankara Üniversitesi, Sosyal Bilimler Enstitüsü, Antropoloji Anabilim Dalı, Ankara - Türkiye ${ }^{2}$ Prof. Dr. | Ankara Üniversitesi, Dil ve Tarih - Coğrafya Fakültesi, Antropoloji Bölümü, Sıhhiye, Ankara - Türkiye
Alındı/Received: 3 Aralık / December 2020 Düzeltildi/Revised: 21 Haziran / June 2021

Kabul/Accepted: 25 Haziran / June 2021 Yayımlandı/Published: 28 Haziran / June 2021

\section{Öz}

İlerleyen yaşlarda kas, eklem ve kemik yapılarda ortaya çıkan kayıplar bireylerde ölçülen boy uzunluğu değerlerini etkilemektedir. Bu çalışmanın amacı yaşlılarda ölçülen boy uzunluğu değerlerini ve diz yüksekliğinden hesaplanan tahminî boy uzunluğu değerlerini karşılaştırmaktır. Bu doğrultuda Ankara'daki huzurevlerinde yaşayan 62-94 yaş aralığındaki 57 kadın ile 50 erkek bireyin boy uzunluğu, diz yüksekliği ve ağırlık ölçümleri alınmıştır. Veriler SPSS programında analiz edilmiş, formüller ise Excel programında hesaplanmıştır. Değişkenler arasındaki ilişkiyi anlamak için bağımsız örneklem $t$-testi ve korelasyon analizi yapılmıştır. Sonuç olarak bireylerden ölçülen boy uzunluğu ile hesaplanan tahmini boy uzunluğu değerleri arasında anlamlı derece fark elde edilmiştir $(p<0,05)$. Yaş ve tahminî boy uzunluğu arasında hafif derecede negatif yönde korelasyon bulunmuştur $(p<0,05)$. Ayrıca kadınlarda erkeklerden daha fazla boy kaybı olduğu sonucuna ulaşılmıştır.

Anahtar Sözcükler: Yaşlılık, diz yüksekliği, boy uzunluğu hesaplama, antropometri

\section{Giriş}

Yaşlanma, insan organizmasının çevresel ve mental faktörlere uyum sağlama kabiliyetinde ortaya çıkan bir azalmadır. Yaşlılık ise çevresel, psikolojik ve fizyolojik etmenlerin etkileşimi sonucunda artan yaşla birlikte yaşlanmaya bağlı olarak ortaya çıkan "yaşlı olma" durumudur (Gültekin ve Varol, 2019). Yaşla birlikte gelen vücut kompozisyonundaki değișisklikler hastalık ya da ölümle ilişkilendirilmektedir (Cape vd., 2007). Erişkinlik döneminden sonra bireylerde boy kaybı gerçekleșmektedir. Erkeklerde daha ileri dönemlerde olmakla beraber bu durum kadınlarda menopozdan sonra belirginleşmektedir (Gültekin, 2004). 50 yaşından sonraki dönemde bireylerde 5 senede bir 2,5 $\mathrm{cm}$ ve 75 yaşından sonra 5 senede bir $5 \mathrm{~cm}$ boy kaybı olduğu bilinmektedir (Akın, 2012). Bu da osteoporoz kaynaklı kemik yoğunluğundaki kayıplardan dolayı bazı antropometrik ölçüm değerlerinde farklliklar ortaya

\section{Examination of measured height and height calculated} from knee height values in the elderly

\section{Abstract}

Loss in muscle, joint and bone structures that occur in later ages affects the measured beight values of individuals. The aim of this study is to compare the measured height values and the estimated height measurement values calculated from the knee height taken from the elderly. Accordingly, height, knee height and weight measurements were taken from 57 female and 50 male individuals between the ages of 62-94 living in the nursing homes in Ankara. The data were analysed in the SPSS program, and the formulae were worked out in the Excel program. Independent sample t-test and correlation analysis were performed to understand the relationship between the variables. As a result, a significant difference was obtained between measured height and calculated estimated beight values in individuals $(\mathrm{p}<0.05)$. A negative low correlation was found between age and estimated height $(\mathrm{p}<0.05)$. In addition, it was concluded that females had more height loss than men.

Key Words: Old age, knee height, height calculation, anthropometry

çıkmasina sebep olur (Roubenof ve Wilson, 1993). Ayrıca kifoz, skolyoz, vertebral disklerin yıpranmasi, bacaklarda eğrileşme, plantar arkın düzleşmesi gibi durumlar yaşlılarda boy uzunluğunun düşük çıkmasına ve BMI değerlerinin fazla hesaplanmasina neden olur. $\mathrm{Bu}$ yanliş tahminler obezite ve yetersiz beslenme prevalans oranlarınin da farklı olmasina neden olmaktadır (Gavriilidou vd., 2015).

Doğru boy ölçümleri gençlerden daha kolay elde edilebilmesine rağmen bu durum yașlılarda her zaman mümkün değildir. Boy uzunluğu ölçümleri hastaların klinik muayenesinde, epidemiyolojik araştırmalarda, yaşlıların enerji gereksinimlerinin belirlenmesinde çok önemli bir yere sahiptir. Özellikle de kardiyovasküler hastalıklarda ağırlık ölçümleriyle birlikte değerlendirilmektedir (Pini vd., 2001; Kuwabara vd., 2011). Bu durumda boy uzunluğu çok sik kullanılan bir antropometrik ölçümdür. Boyu belirlemek için diz 
yüksekliğinin ölçülmesi ile bireylerden boy uzunluğu tahminleri yapilabilmektedir (Udoh vd., 2017). İlerleyen yaşla beraber yaşlı kişilerde boyun belirlenmesi zorlaşmaktadır. Bunun için diz yüksekliğinden yola ç1kılarak çeşitli denklemler geliştirilmiştir (Chumela vd., 1985). Chumlea tarafindan geliştirilen diz yüksekliğinden boy tahmini formülü çok yaygın olarak kullanılmaktadır (Yamanaka vd., 2010).

Antropometrik çalışmaların sağlık, ergonomi, spor gibi alanlarda yeri büyüktür. Ülkemizde 1917 y1lından beridir antropometrik ölçümlere dayalı çalışmalar yapılmaktadır (Kaya ve Özok, 2017). Bu çalışmanın amac1 60 yaş ve üzeri bireylerde boy kısalmasının ne derece olduğunu ortaya koymaktır. Bu doğrultuda Ankara'da yaşayan 60 yaş ve üzeri bireylerde ölçülen boy uzunluğu değerleri ve diz yüksekliği formüllerinden hesaplanan tahmini boy uzunluğu değerleri arasındaki farkın karşılaştırılması amaçlanmaktadır. TÜİK (2020) verilerine göre ülkemizde yaşlı nüfusunun son 5 yılda $\% 21,9$ oranında artmış olduğu görülmektedir. Bu nedenle çalışmamızın ülkemizdeki yaşlı popülasyonu için veri toplanması açısından da fayda sağlayacağı düşünülmektedir.

\section{Gereç ve yöntem}

Bu çalışma Ankara'da Aile Sosyal ve Politikalar Bakanlığı'na resmi olarak bağlı huzur evlerinden seçilen 62-94 yaş aralığındaki 57 kadın ile 50 erkek birey üzerinde yapilmışır (Tablo 1).

Tablo 1. Katılımcılarn cinsiyete göre dağzlımı

\begin{tabular}{cc}
\hline Cinsiyet & N \\
\hline Kadın & 57 \\
Erkek & 50 \\
Toplam & 107 \\
\hline
\end{tabular}

Çalışmanın yapılabilmesi için Ankara Üniversitesi Etik Kurulu onay1 (08.04.2019/126) ve Aile, Çalışma ve Sosyal Hizmetler Bakanlı̆ı onay1 (73595336-605.01/6) alınmıştır. Çalışmaya katılacak bireylerin araştırmaya gönüllü olduklarını beyan eden onam formu taraflarınca imzalanarak onamları alınmıştır. Katılımcılara çalışma hakkında gerekli bilgiler detaylıca verilmiştir. Seçilen kişilerin fiziksel olarak ciddi bir rahatsızlığ bulunmamaktadır.

Katılımcılardan alınan ölçümler şu şekildedir:

- Otururken diz yüksekliği: Birey sandalyeye üst ve alt bacaklarının kemiklerinin bileşim yerleri 90 derece açıda bükük olacak şekilde oturur. Antropometre sol bacağın yanına getirilir ve yatay uç dizin en yüksek noktasına sabitlenerek ölçülür.

- Ölçülen boy uzunluğu: Baş Frankfurt planında iken
Martin tipi antropometre ile metal uç başın en tepe noktası olan verteks bölgesine konularak ölçülür. Ölçümler bireylerin sol tarafından alınmıştır.

- Ağırlık: Ağırlık ölçümü 100 grama duyarlı dijital tartı (TANITA BF-556 Body Fat Monitor) ile gerçekleştirilmiştir.

- Tahmini boy uzunluğu: İleri yaş grubu bireylerde boy gittikçe kısalmaktadır. Bu bireylerde diz yüksekliği ölçümüne dayalı boy formülleri kullanılmaktadır (Özgün Baş1büyük vd., 2017). Bu çalışmada yaş ve otururken diz yüksekliği ölçümlerinden üretilen boy uzunluğu hesaplanmıştır.

Erkekler $=64.19-(0.04 \mathrm{X}$ Yaş $)+(2.02 \mathrm{X}$ Diz
Yüksekliği $)$
Kadinlar $=84.88-(0.24 \mathrm{X}$ Yaş $)+(1.83 \mathrm{X}$ Diz
Yüksekliği) (Chumlea vd., 1985).

Ölçümler International Biological Programme (IBP) ve Anthropometric Standardization Reference Manual (ASRM)'ın öngördüğü teknikler doğrultusunda gerçekleştirilmiştir (Weinner ve Louire, 1969).

\section{Verilerin istatistiksel analizi}

TümverilerSPSS20 programındaişlenmiştir. Değişkenler arasındaki ilişkiyi değerlendirmek için bağımsız örneklem $t$-testi ve korelasyon analizi yapılmıştır. Diz yüksekliğinden boy uzunluğu hesaplamaları ise verilen formüller Excel programına girilerek analiz edilmiştir.

\section{Bulgular}

Katılımcıların antropometrik verilerine ilişkin değerlerin gösterildiği Tablo 2'ye göre kadınlarda ortalama

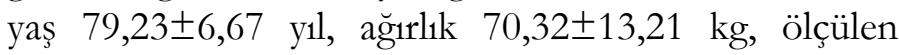
boy uzunluğu $151 \pm 6,52 \mathrm{~cm}$, tahmini boy uzunluğu $155,5 \pm 4,67 \mathrm{~cm}$, diz yüksekliği $49,1 \pm 2,54 \mathrm{~cm}$ olarak bulunmuştur. Erkeklerde ise ortalama yaş $77,8 \pm 7,58$ y1l, ağırlık $78,47 \pm 10,77 \mathrm{~kg}$, ölçülen boy uzunluğu $164,45 \pm 5,82 \mathrm{~cm}$, tahmini boy uzunluğu $167,13 \pm 3,47 \mathrm{~cm}$, diz yüksekliği $52,5 \pm 1,7 \mathrm{~cm}$ olarak bulunmuştur. Ayrıca cinsiyetler arasında ölçülen boy uzunluğu, tahmini boy uzunluğu, ağırlık ve diz yüksekliği ölçümlerinde anlamlı derecede fark gözlemlenmiştir $(p<0,005)$.

Cinsiyetler arasinda ölçülen boy uzunluğu ve tahmini boy uzunluğu değerleri fark1 ise Tablo 3’te verilmiştir. Buna göre, kadınlarda ölçülen boy uzunluğu ve tahmini boy uzunluğu değerleri arasında ortalama 4,56 $\mathrm{cm}$, erkeklerde ise ortalama 2,67 cm fark bulunmuştur. Bu durumda ölçüm aldığımız kadın bireylerde; erkek bireylere göre $1,89 \mathrm{~cm}$ daha fazla boy uzunluğu değeri kısa çıkmıştır.

Bireylerin antropometrik ölçüm değerleri arasındaki korelasyon değerlerini gösteren Tablo 4'e göre tahmini boy uzunluğu-ölçülen boy uzunluğu, tahmini boy 
Tablo 2. Katılimcularn fiziksel özellikleri

\begin{tabular}{cccc}
\hline & $\begin{array}{c}\text { Kadın } \\
\text { (N=57) }\end{array}$ & $\begin{array}{c}\text { Erkek } \\
\mathbf{( N = 5 0 )}\end{array}$ & \\
\hline Ölçümler & Ort. (SS) & Ort. (SS) & $\boldsymbol{p}$ \\
\hline Yaş (yıl) & $79,23(6,67)$ & $77,8(7,58)$ & 0,302 \\
Ağırlık (kg) & $70,32(13,21)$ & $78,47(10,77)$ & $0,001^{* * *}$ \\
Ölçülen boy uzunluğu (cm) & $151(6,52)$ & $164,45(5,82)$ & $<0,001^{* * *}$ \\
Tahmini boy uzunluğu (cm) & $155,50(4,67)$ & $167,13(3,47)$ & $<0,001^{* * *}$ \\
Diz yüksekliği (cm) & $49,01(2,54)$ & $52,5(1,7)$ & $<0,001^{* * *}$ \\
\hline
\end{tabular}

Not: Ort. = Ortalama, $S S=$ Standart sapma

${ }^{*} p=0,05$ düzeyinde anlamlıdır, ${ }^{* *} p=0,01$ düzeyinde anlamlıdır, ${ }^{* * *} p=0,001$ düzeyinde anlamlıdır.

Tablo 3. Katılımcılarn cinsiyete göre dağzlım

\begin{tabular}{ccc}
\hline Cinsiyet & Asıl boy uzunluğu-hesaplanan boy uzunluğu ort. $(\mathbf{c m})$ & $\boldsymbol{p}$ \\
\hline Kadın & $-4,56(4,59)$ & $<0,001^{* * *}$ \\
Erkek & $-2,67(4,08)$ & $<0,001^{* * *}$ \\
\hline
\end{tabular}

Not: Santimetre cinsinden verilen ölçümlerde illk değer ortalama, parantez içindeki değer standart sapmadır.

${ }^{*} p=0,05$ düzeyinde anlamlıdır, ${ }^{* *} p=0,01$ düzeyinde anlamlıdır, ${ }^{* * *} p=0,001$ düzeyinde anlamlıdır.

Tablo 4. Değiskeenlerin korelasyon analizi

\begin{tabular}{lcc}
\hline \multicolumn{1}{c}{ Değişkenler } & Korelasyon değeri & $\boldsymbol{p}$ \\
\hline Tahmini boy uzunluğu-ölçülen boy uzunluğu & 0,880 & $<0,001^{* * *}$ \\
Tahmini boy uzunluğu-cinsiyet & 0,814 & $<0,001^{* * *}$ \\
Diz yüksekliği-tahmini boy uzunluğu & 0,944 & $<0,001^{* * *}$ \\
Diz yülksekliği-ölçülen boy uzunluğu & 0,830 & $<0,001^{* * *}$ \\
\hline
\end{tabular}

${ }^{*} p=0,05$ düzeyinde anlamlıdır, ${ }^{* *} p=0,01$ düzeyinde anlamlıdır, ${ }^{* * *} p=0,001$ düzeyinde anlamlıdır.

uzunluğu-cinsiyet, diz yüksekliği-tahmini boy uzunluğu, diz yüksekliği-ölçülen boy uzunluğu değişkenleri arasında pozitif yönde anlamlı fark bulunmuştur $(p<0,05)$.

\section{Tartışma}

Ülkemizde konuyla ilgili yapılan çalışmalara bakıldığında Aktan Korkmaz ve Özgün Başıüyük (2013), Sivas'ta yaşayan 65 yaş üzeri 57 kadın, 47 erkek bireyde ölçülen boy uzunluğunu sirasiyla ortalama $151,4 \mathrm{~cm}$ ve $163,8 \mathrm{~cm}$ olarak bulmuștur. Bu değerler çalıșmamızdaki kadın ve erkeklerdeki normal boy uzunluğu değerleri ile benzerlik göstermektedir.

Özgün Başıüyük ve ekibi (2018), Türkiye genelindeki huzur evlerinde 160 erkek ve 170 kadın birey üzerinde yaptıkları çalışmada tahmini boy değerlerini sirasiyla ortalama olarak 169,3 cm ve $162,2 \mathrm{~cm}$ olarak bulmuştur. $\mathrm{Bu}$ değerler çalışmamızdaki hesaplanan boy değerleri ile benzerlik göstermemektedir. Aynı çalışmada diz yüksekliği kadınlarda ortalama 50,3 $\mathrm{cm}$, erkeklerde ise 53,6 cm olarak tespit edilmisstir. $\mathrm{Bu}$ sonuçlar çalışmamızdaki diz yüksekliği değerleri ile benzerlik göstermektedir. İki çalışmada da cinsiyetler arasında anlamlı düzeyde farklılık bulunmuştur.

Gültekin (2004), Ankara'da yaşayan 65 yaş üzeri 91 kadın, 73 erkek bireyde diz yüksekliği değerlerini sırası ile ortalama $47 \mathrm{~cm}$ ve $51,5 \mathrm{~cm}$ olarak bulmuştur. Ölçülen boy değerleri ise kadınlarda ortalama 149,37 cm, erkeklerde $163,72 \mathrm{~cm}$ olarak bulmuştur. Erkeklerdeki boy ölçümü dıșındaki diğer değerler çalıșmamızın sonuçları ile benzerlik göstermese de cinsiyetler arasındaki farkı net bir şekilde göstermektedir. Özgün Başıüyük ve ekibi (2016), İç Anadolu, Karadeniz ve Akdeniz bölgelerindeki bazı şehirlerden 989 kadın ve erkek bireyin ölçülen boy uzunluklarını sirasiyla ortalama $148,1 \mathrm{~cm}$ ve $164 \mathrm{~cm}$ olarak tespit edilmiştir. Erkek bireylerin ölçülen boy uzunluğu değerleri çalışmamız sonuçlarıyla benzerlik gösterirken kadınlarınki göstermemektedir.

Ersoy Özütürker (2009), Erzincan'da ikamet eden 
65 yaş üstü 200 kadın ve 200 erkek birey üzerinden çeşitli antropometrik ölçümler almıştır. Buna göre diz yüksekliği kadınlarda ortalama 47,95 $\mathrm{cm}$, erkeklerde $51,30 \mathrm{~cm}$ olarak bulunmuştur. Ölçülen boy uzunluğu kadinlarda ortalama $153,20 \mathrm{~cm}$, erkeklerde ise 165 $\mathrm{cm}$ olarak tespit edilmiştir. Bu sonuçlar çalışmamızla benzerlik göstermemektedir.

Özgüneş (2013), İstanbul'da yaşayan yaş ortalaması 75 yil olan 53 erkek ve yaş ortalaması 81 yil olan 26 kadın bireyin ölçülen boy uzunluğu değerlerini sırası ile ortalama $164 \mathrm{~cm}$ ve $149,7 \mathrm{~cm}$ olarak bulmuştur. Diz yüksekliği ise kadınlarda 47,2 cm, erkeklerde 51,1 cm olarak tespit edilmiştir. Saruhan ve Pekcan (2001), Ankara'daki huzur evlerinden seçtikleri yaş ortalaması 73 yıl olan 100 erkek ve yaş ortalaması 72,2 yıl olan 150 kadın bireyde boy formülü ile hesaplamalar yapmıştır. Buna göre erkeklerde tahmini boy uzunluğu ortalama $164,4 \mathrm{~cm}$, kadınlarda $150,4 \mathrm{~cm}$ olarak bulunmuștur. Erkeklerde otururken diz yüksekliği ortalama 51,9 $\mathrm{cm}$, kadınlarda ise $47,3 \mathrm{~cm}$ olarak tespit edilmiştir. $\mathrm{Bu}$ sonuçlar ölçüm değerleri açısından çalışmamızdaki değerlerle benzerlik göstermemektedir.

Pini ve ekibi (2001), İtalya'da 258 kadın ve erkek birey üzerinde yaptıkları çalışmada 65-74 yaş gurubu kadınlarda diz yüksekliğini $48 \mathrm{~cm}$, erkeklerde $52 \mathrm{~cm}$ olarak bulmuşlardır. 75-84 yaş gurubu kadınlarda 47 $\mathrm{cm}$, erkeklerde $50 \mathrm{~cm}, 85$ yaş ve üzeri kadınlarda $46 \mathrm{~cm}$, erkeklerde $50 \mathrm{~cm}$ olarak belirlemişlerdir. 1989 ve 1995 yılları arasında yaptıkları boy karşılaştırmalarında 7074 yaş grubu erkeklerde ölçülen boy uzunluğunun 166 cm'den 165 cm'ye, 75-84 yaş grubunda 163 cm'den 162 cm'ye, 85 yaş ve üzerinde 163 'den 162 cm'ye düştüğünü tespit etmişlerdir. Kadınlarda ise bu süreçte ölçülen boy uzunluğu değerlerinin yaş gruplarına göre sırası ile 155 cm'den 153 cm'ye, 152 cm'den 149 cm'ye, 149 cm'den 147 cm'ye düştüğünü tespit etmişlerdir. Buna göre ilerleyen yaşla beraber en çok kadınlarda olmakla birlikte iki yaşta da boy kısalığı olduğunu gözlemlemişlerdir. Bu sonuç çalışmamız ile benzerlik göstermektedir.

Gavriilidou ve ekibi (2015), 65 yaş ve üzerindeki İsveçli 2839 kadın ve erkek bireye diz yüksekliği formüllerinden boy hesaplamaları yapmışlardır. Erkeklerde tahmini boy uzunluğunu 65-69 yaş grubunda $0,7 \mathrm{~cm}, 70-74$ yaş grubunda $1,1 \mathrm{~cm}, 75-79$ yaş grubunda $2,8 \mathrm{~cm}, 80-84$ yaş grubunda $3,2 \mathrm{~cm}, 85$ yaş ve üzeri grupta ise 3,6 cm fazla olarak tespit edilmiştir. Kadınlarda 6064 yaş grubunda $0,1 \mathrm{~cm}, 65-69$ yaş grubunda $1,2 \mathrm{~cm}$, $70-74$ yaş grubunda $3,1 \mathrm{~cm}, 75-79$ yaş grubunda $3,8 \mathrm{~cm}$, $80-84$ yaş grubunda $4,8 \mathrm{~cm}, 85$ yaş ve üzeri grupta 6,7 $\mathrm{cm}$ fazla olarak bulunmuştur. Genel olarak erkeklerde ölçülen boy uzunluğu 174,8 cm, tahmini boy uzunluğu $176,3 \mathrm{~cm}$, kadınlarda ölçülen boy $160,7 \mathrm{~cm}$, tahmini boy uzunluğu 163,8 cm bulunmuştur. Erkeklerde 1,5 cm kısalma, kadınlarda ise 3,1 cm kısalma olduğu tespit edilmiștir. Boy uzunlukları açısından benzerlik olmasa da bu çalışma, ilerleyen yaşla beraber hem boy kısalığ1 hem de cinsiyet farkları açısından çalışmamızla benzerlik göstermektedir.

Fogal ve ekibi (2015), Brezilya'daki 547 erkek, 273 kadın olmak üzere 60-79 yaş aralığındaki bireylerde boy uzunluğu hesaplamaları yapmışlardır. Erkeklerde ortalama ölçülen boy uzunluğu ve tahmini boy uzunluğu değerleri sırası ile $165,5 \mathrm{~cm}$ ve $165,6 \mathrm{~cm}$ olarak bulunmuştur. Kadınlarda ise bu değerler sırası ile 152,2 cm ve 154,6 cm olarak belirlenmiştir. Genel olarak boy uzunluğunda 1,2 cm kayıp gözlemlenmiştir. Kadınlarda diz yüksekliği $47,3 \mathrm{~cm}$, erkeklerde ise $51,6 \mathrm{~cm}$ olarak bulunmuştur. Erkeklerde sonuç çok değişmemesine rağmen kadınlarda tahmini boy uzunluğu $2,2 \mathrm{~cm}$ fazla bulunmuştur. Boy kısalması açısından ortaya çıkan cinsiyet farkı, erkeklerde diz yüksekliği ve ölçülen boy uzunluğu, kadınlarda tahmini boy uzunluğu ölçümleri çalışmamız sonuçları ile benzerlik göstermektedir.

Murbawani ve ekibi (2012), Chumela formülünden yola çıkarak 59-88 yaş aralığındaki Endonezyalı toplam 86 kadın ve erkek bireyde boy tahminleri yapmışlardır. Diz yüksekliği kadınlarda ortalama $47,3 \mathrm{~cm}$, erkeklerde 50 cm olarak tespit edilmiştir. Ölçülen boy kadınlarda 146,8 cm, tahmini boy $154,3 \mathrm{~cm}$; erkeklerde ölçülen boy 160,8 $\mathrm{cm}$, tahmini boy 159,1 cm olarak bulunmuştur. Diz yüksekliği kadınlarda ortalama $47,2 \mathrm{~cm}$, erkeklerde ise 50 cm bulunmuştur. Bu çalışma kadınlarda ortaya çıkan boy farklılı̆̆ı açısından çalışmamızla benzerlik göstermekte ancak erkekler için benzerlik göstermemektedir. Fatmah (2010), yaşları 55-84 arasında değişen Endonezyalı kadın ve erkek bireyler üzerinde yaptığı çalışmada Chumela'nın boy hesaplama formülünden elde ettiği verilere göre cinsiyetler arasında ölçülen boy uzunluğu ve tahmini boy uzunluğu arasında farklılık gözlemlemiştir. Erkeklerdeki boyda azalma kadinlara oranla daha az bulunmuştur. Aynı şekilde Celeste ve ekibi (2002), 60 yaş üzeri kadınlarda boy kısalmasını 4,22 cm, erkeklerde ise 2,7 cm olarak hesaplamıştır (Fatmah, 2010). Chumela ve ekibi (1985), yaşları 68 üzeri olan 63 kadın ve erkek birey üzerinde ölçülen boy uzunluğunu ortalama 153,05 $\mathrm{cm}$, tahmini boy uzunluğunu ise $158,10 \mathrm{~cm}$ olarak bulmuşlardır. Ölçülen boy uzunluğu ile tahmini boy arasında ortalama $5,05 \mathrm{~cm}$ fark ile anlamlı derecede ilişki gözlemlemişlerdir. Bu sonuç çalışmamızın sonuçlarıyla benzerlik göstermektedir (Silva vd., 2018).

Yaşlilık döneminde kadınlarda ortalama olarak 4,9 $\mathrm{cm}$, erkeklerde de 2,9 $\mathrm{cm}$ boy kısalması gerçekleştiği bilinmektedir (Gültekin, 2004). Çalışmamızdan elde edilen verilere göre kadınlarda ölçülen boy uzunluğuna göre boy uzunluğunda kısalma ortalama $4,56 \mathrm{~cm}$, erkeklerde ise 2,67 olarak bulunmuştur. Çin'de gerçekleştirilen bir araştırmada diz yüksekliğinden boy uzunluğu hesaplamaları yapıldığında kadınlarda boy 
uzunluğunu $1,7 \mathrm{~cm}$ fazla, erkeklerde ise $3,7 \mathrm{~cm}$ daha az hesaplanmıştır. Japonya'da yapılan bir çalışmada diz yüksekliğinden hesaplanan tahmini boy uzunluğu kadinlarda $1,5 \mathrm{~cm}$ daha fazla, erkeklerde $1,2 \mathrm{~cm}$ daha az olarak bulunmuştur. İsveç'te erkeklerde ise $2 \mathrm{~cm}$ fazla, kadınlarda $1 \mathrm{~cm}$ az tahmin edilmiştir. Pertiwi ve ekibi (2018), Endonezya'da 60-69 yaș aralığındaki bireylerde tahmini boy uzunluğunu kadınlarda ölçülen boy uzunluğuna göre ortalama $6,1 \mathrm{~cm}$, erkeklerde ise 0,3 $\mathrm{cm}$ fazla olarak bulmuşlardır.

\section{Sonuç}

Sonuç olarak yapılan çalışmada kullanılan boy uzunluğu formüllerinden elde edilen sonuçlar ilerleyen yaş ile boy uzunluğunda kayıplar olduğunu ortaya koymuştur. Bu kayıplar cinsiyetler arasındaki farkı da göstermektedir. Kadınlarerkeklereoranlaileriyaşlarda daha fazlaboykaybı yaşamışlardır. Yapılan bazı çalışmalar bu formüllerden elde edilen değerleri desteklerken bazı çalışmalar desteklememektedir. Ülkemizde yaşlı popülasyona yönelik daha geniş alanda yapılacak çalışmaların, elde edilen referans değerler ile yeni denklemler gelişmesine katkı sağlayacağı düşünülmektedir.

\section{Teşekkür}

Bu çalışma 100/2000 YÖK Doktora Bursiyer Program1 "Yaşlılık Çalışmaları" kapsamında yapılmıştır.

\section{Kaynakça}

Akın, G. (2012). Ergonomi. Tiydem Yayıncılık.

Aktan Korkmaz, B., ve Özgün Başıüyük, G. (2013). Sivas İli 50 Yaş ve üzeri bireylerinde obezite. Antropoloji, (26), 55-72. https://doi.org/10.1501/antro_0000000106

Cape, W., Marias, D., Marais, M.L., ve Labadorios, D. (2007). Use of knee height as a surrogate measure of height in older South Africans. South African Journal of Clinical Nutrition, 20(1), 34-44. https://doi.org/10.1080/16070658.2007.11734120

Chumlea, W. C., Roche, A.F., Steinbaugh, M, L. (1985). Estimating stature from knee height for persons 60 to 90 years of age. Journal of the American Geriatrics Society, 33(2), 116-120. https:// doi.org/10.1111/j.1532-5415.1985.tb02276.x

Ersoy Özütürker, S. (2009). Yaşlı bireylere yönelik referans değerleri: Erzincan örneği. Yaşl Sorunlar Araştırma Dergisi, 2, 126-135.

Fatmah, (2010). Diagnostic test of predicted height model in Indonesian elderly: A study in an urban area. Medical Journal of Indonesia, 19(3), 199-204. https://doi.org/10.13181/mji. v19i3.405

Fogal, A. S., Franceschini, S. D. C. C., Priore, S. E., Cotta, R. M. M., ve Ribeiro, A. Q. (2015). Stature estimation using the knee height measurement amongst Brazilian elderly. Nutricion Hospitalaria, 31(2), 829-834.

Gavriilidou, N. N., Pihlsgård, M., ve Elmståhl, S. (2015). High degree of BMI misclassification of malnutrition among Swedish elderly population: Age-adjusted height estimation using knee height and demispan. European Journal of Clinical Nutrition, 69, 565-571. https://doi.org/10.1038/ejcn.2014.183

Gültekin, T. (2004). Ankara'da yaşayan erişkin bireylerin vücut bileșimi değerleri [Yayımlanmamış doktora tezi]. Ankara Üniversitesi Sosyal Bilimler Enstitüsü.

Gültekin, T., ve Varol, N. (2019). Disasters and the elderly: The Turkey case. Papers on Anthropology, 28(1), 36-46. https:// doi.org/10.12697/poa.2019.28.1.03

Kaya, Ö., ve Özok, A.F. (2017). Tasarımda antropometrinin önemi. Mühendislik Bilimleri ve Tasarm Dergisi, 5, 309-316. https:/ / doi. org/10.21923/jesd.45182

Kuwabara, A., Shimokawa, Y.O., ve Tanaka, K. (2011). Body weight divided by squared knee height as an alternative to body mass index. Medical Hypothesis, 76(3), 336-338., https:// doi.org/10.1016/j.mehy.2010.10.033

Murbavani, E.A.Murbavani, E.A., Puruhita, N., Yudomurti, (2012). Tinggi badan yang diukur dan berdasarkan tinggi lutut menggunakan rumus Chumlea pada lansia. Media Medika Indonesiana, 46(1), 1-6.

Özgün Başıüyük, G., Bektaş, Y., Çınar, Z., Ay, F., ve Bekdaş, O. (2018). Yaşlı bireylerin tuvalet-banyo tasarımına yönelik antropometrik ölçüleri ve pazardaki ürünlerin yaşlyya uygunluğunun değerlendirilmesi. Mühendislik Bilimleri ve Tasarm Dergisi, 6, 248-256. https://doi.org/10.21923/ jesd. 358580

Özgün Başıüyük, G., Bektaş, Y., Çınar, Z., Ay, F., ve Alan, A. (2017). Huzurevinde kalan yaşlilarda malnütrisyon sıklığı. Ahi Evran Üniversitesi Sosyal Bilimler Enstitüsü Dergisi, 3(2), 339-348.

Özgün Başıüyük, G., Çınar, Z., Ay, F., Sönmez, G., (2016). Yaşlılara yönelik medikal aparat tasarımında kullanılan bazı antropometrik ölçülerin referans değerleri: İç Anadolu, Akdeniz ve Karadeniz bölgeleri. Yaşh Sorunlar Arastırma Dergisi, 9, 48-63.

Özgüneş, N., (2013). Huzurevinde yaşayan yaşlılarda beslenme durumunun taranmasi: Tarama testleri kiyaslaması [Yayımlanmamış yüksek lisans tezi]. Hacettepe Üniversitesi Sağlık Bilimleri Enstitüsü.

Petiwi, J., Kartasurya, M.E., Lukmono, D.T.H., Setyawan, H., ve Martini, M. (2018). A calculating actual stature of elderly through arm span and knee height measurements. Health Notions, 2(2), 265-270.

Pini, R., Tonon, E., Cavallini M.C., Bencini, F., Di Bari, M., Masotti, G., ve Marchionni, N. (2001). Accuracy of equations for predicting stature from knee height, and assessment of statural loss in an older Italian population. The Journals of Gerontology: Series A, 56(1), B3-B7. https://doi.org/10.1093/ gerona/56.1.B3

Roubenoff, R., ve Wilson, P. W. (1993). Advantage of knee height over height as an index of stature in expression of body composition in adults. The American Journal of Clinical Nutrition, 
57(5), 609-613. https://doi.org/10.1093/ajcn/57.5.609

Saruhan, S., ve Pekcan, G. (2001). Yaşlilarda antropometrik yöntemlerle beslenme durumunun değerlendirilmesi, boy uzunluğu ve vücut ağırlı̆̆ının saptanmasında denklemler. Beslenme ve Diyet Dergisi, 30(2), 32-41.

Silva A. P. N., Oliveira, C. C., Silva, G.C., ve Santos, G.A. (2018). Estimated body weight and height in older adults: Agreement between methods. Geriatrics, Gerontology and Aging, 12(2), 7480. https://doi.org/10.5327/Z2447-211520181800025

Türkiye İstatistik Kurumu (TÜİK) (2020). Istatistiklerle yaşllar, 2019. https://data.tuik.gov.tr/Bulten/Index?p=IstatistiklerleYaslilar-2019-33712

Udoh U. G., Peter A. I., Thomas D. F., ve Johnson E. I., (2017). Estimation of stature of the Annang ethnic group of Nigeria using knee height. International Journal of Healthcare and Medical Sciences, 3(9), 55-61.

Weiner, J. S., ve Lourie, J. A. (1969.) Human biology: A guide to field methods. Blackwell Scientific Publications.

Yamanaka, K., Ishida, S., Susaki, H., Kojima, C., Omine, N., Itoh, Y., Hirata, Y., Okada, K., Sumiya, A., ve Toba, M. (2010). Estimating stature from knee height for elderly females aged 60-80 years old in Aichi Prefecture, Japan. Annual Report of Institute of Health and Nutrition, Nagoya University of Arts and Sciences, (4), 1-10. https://www.nuas.ac.jp/IHN/report/ pdf/04/01.pdf

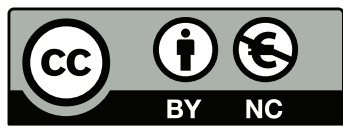

2021. Telif hakları yazar(lar)a aittir.

Bu makale Creative Commons Atıf-GayriTicari 4.0 Uluslararası (CC BY-NC 4.0) lisansının hüküm ve şartları altında yayımlanan açık erişimli bir makaledir. 